Brazilian Journal of Political Economy, vol. 40, n 4, pp. 746-765, October-December/2020

\title{
Thorstein Veblen's Institutional Economics and Daniel Kahneman and Amos Tversky's Behavioral Economics: an analysis of convergent points
}

\author{
A Economia Institucional de Thorstein Veblen \\ e a Economia Comportamental de Daniel Kahneman \\ \& Amos Tversky: uma análise de pontos convergentes
}

TAINARI TAIOKA*

FELIPE ALMEIDA ${ }^{+}$

RAMÓN GARCÍA FERNÁNDEZ ${ }^{x}, x x$

\begin{abstract}
RESUMO: A Economia Institucional original e a Economia Comportamental são duas abordagens que desafiaram a tomada de decisão da economia convencional de seu tempo. Dessa forma, partindo de uma análise da Economia Institucional original sustentada por Thorstein Veblen e da Economia Comportamental de Daniel Kahneman e Amos Tversky, o presente estudo tem como objetivo analisar se existem elementos convergentes nessas abordagens. Como a questão central deste artigo é a tomada de decisão, a convergência entre essas abordagens se debruça sobre suas bases psicológicas. A base psicológica da Economia Institucional original corresponde à filosofia pragmática norte-americana. Este estudo oferece uma abordagem psicológica do aprendizado social e a teoria da dissonância cognitiva como a base psicológica da Economia Comportamental.

PALAVRAS-CHAVE: Economia Institucional original; Economia Comportamental; Thorstein Veblen; Daniel Kahneman; tomada de decisão.
\end{abstract}

ABSTRACT: Original Institutional Economics and Behavioral Economics are two approaches that have challenged the conventional economics of their time regarding decision-making. Therefore, considering the original Institutional Economics according to Thorstein Veblen

\footnotetext{
* Universidade Federal do ABC - UFABC, Santo André/SP, Brasil. E-mail: tainaritaioka@gmail.com. Orcid: https://orcid.org 0000-0001-9035-0626.

+ Universidade Federal do Paraná - UFPR, Curitiba/PR, Brasil. E-mail: felipe.almeida@ufpr.br. Orcid: https://orcid.org/0000-002-3792-793X.

× Universidade Federal do ABC - UFABC, Santo André/SP, Brasil. E-mail: ramon.garcia.fernandez@ gmail.com. Orcid: https://orcid.org/0000-0002-4198-0792.

${ }^{x x}$ A previous version of this paper was presented at the 47th ANPEC meeting, São Paulo, December 2019. The authors thank the participants in this event, especially Gustavo Goulart, for their insightful comments. Submitted: 17/February/2020; Approved: 25/March/2020.
} 
and Behavioral Economics as stated by Daniel Kahneman and Amos Tversky, this study aims to analyze if they have any convergent elements. As the key issue investigated in this study is decision-making, the convergence among these approaches relies on their psychological foundations. The psychological basis of original Institutional Economics is North-American pragmatic philosophy. This study offers a psychological approach to social learning and the theory of cognitive dissonance as the psychological basis of Behavioral Economics.

KEYWORDS: Original Institutional Economics; Behavioral Economics; Thorstein Veblen; Daniel Kahneman; decision-making.

JEL Classification: B52; D03.

\section{INTRODUCTION}

Economic science is a field of knowledge involving much debate, with practically nonexistent general agreements. Several perspectives coexist in a non-harmonious way and are sharply debated within the field. However, in quantitative terms, and especially when considering the Anglo-American academic world, there is certainly a majority current to which several minority perspectives are opposed, with greater or lesser affinities among them and/or with the majority current. This current does not have a consensual denomination. Due to the lack of a better name, we use the term mainstream, which according to Dequech (2007), is the best definition for such a current of thought (see also Colander, 2000). For Dequech (2007), mainstream is a term used to name a current of thought, prevalent at a given time, which denotes an essentially sociological fact, without referring to the specifics of the current view. Therefore, the mainstream comprises a set of ideas defended by professionals in the field, which stand out in quantitative terms in relation to other currents. This predominance is verified, both within academic and organizational institutions as well as in research institutes, in the definition of academic curricula, and elsewhere ${ }^{1}$. The divergent currents, in turn, despite the differences among them, are collectively called heterodox, simply for opposing the mainstream.

These differences among schools are manifested in many situations in the analysis of decision-making. The latter is a central theme in economic science, so much so that it has been defined as the "science of choice" by some thinkers. The usual approach to decision-making in economics is that of the economic mainstream, within which decision-makers are commonly analyzed as optimizing, rational, and independent agents. Thus, psychological issues - for example, the process of representing reality or the influence of social interaction on choice - are

\footnotetext{
${ }^{1}$ The current economic mainstream can be understood as an evolution of Neoclassical Economics. These currents of thought are often confused, although there are significant differences among them (Colander, 2000). The initial foundation of this school is Marginalism, a current of thought that became popular in economic science in the last decades of the 19th century but later, due to the contributions of the beginning of the 20th century, it became more known as the Neoclassical School.
} 
treated marginally or are not part of such an analysis. In the late 19th and early 20th centuries, a heterodox school, original Institutional Economics, questioned the decision-making approach of the school of economic thought that would become the mainstream (see Veblen 1898, 1899a, 1899b, and 1900). During the first decades of the twentieth century, original Institutional Economics was a prominent branch of economics (Hodgson, 2004a, and Rutherford, 2011). According to Rutherford (2011), original Institutional Economics competed with Neoclassical Economics for the mainstream position of economic science. For Hodgson (2004a), original Institutional Economics became the mainstream of economics for a short period.

Years later, another school would make a strong criticism of the mainstream perspective. Indeed, Behavioral Economics, led by Daniel Kahneman and Amos Tversky (K\&T), would indicate serious problems in the majority view regarding decision-making. Indeed, the impact of their criticism was very successful, and, at the same time, quite restricted to a specific area - to the point that, to some extent, the mainstream incorporated this criticism as a special case ${ }^{2}$. It can even be argued, according to Dequech's (2007) criteria, that Behavioral Economics could be classified as part of the mainstream. The greatest example of this would be the Nobel Prizes in Economics awarded to Daniel Kahneman, in 2002, and to another key author of that school, Richard Thaler, in $2017^{3}$. Although Behavioral Economics is now tolerated by the mainstream, it certainly cannot be interpreted as an evolution of Neoclassical Economics. Behavioral Economics deals with decision-makers who are not optimizers and who struggle to be as rational as they would like. More precisely, since its origins, K\&T's intellectual project has been guided by the use of elements of psychology to present a strong critique of conventional decision-making in economics (e.g., in their much-cited article on the theory of prospects; K\&T, 1979). Hence, it can be said that, initially, K\&T's writings were more critical than propositional. It was only in a later period that it became possible to perceive studies by Kahneman as propositional.

Considering original Institutional Economics and Behavioral Economics side by side, we compare these two approaches that challenged the conventional economics of their time regarding decision-making. Accordingly, based on an analysis of original Institutional Economics as stated by Veblen and of Behavioral Economics as proposed by K\&T, the present study aims to analyze whether there are converging elements in these two approaches ${ }^{4}$. Since the central issue is decision-making, our study of the possible convergence between these approaches relies on their

\footnotetext{
${ }^{2}$ The criticism of other proponents of Behavioral Economics, such as Herbert Simon, is much more difficult to reconcile with the mainstream. On the other hand, some more recent authors, such as Matthew Rabin and David Laibson, clearly indicate that their work is a complement to and not a criticism of the dominant view. Some authors consider that there are several differences between an "Old" and a "New" Behavioral Economics (see Sent, 2004).

${ }^{3}$ Amos Tversky did not win the Nobel Prize because he died prematurely in 1996. However, the justification for the prize awarded to Kahneman makes clear references to the work they developed jointly.

${ }^{4}$ We do not know of many works studying the relationship between original Institutional Economics
} 
psychological bases. The psychological basis of original Institutional Economics is North American pragmatic philosophy. As the psychological basis of Behavioral Economics, we consider the psychological approach to social learning and the theory of cognitive dissonance.

The rest of this paper is structured as follows: The second section presents the original Institutional theory according to the Veblenian tradition, highlighting how the North American pragmatic philosophy influenced "Veblenian psychology." The third section introduces K\&T's Behavioral Economics, emphasizing its psychological bases: the theory of social learning and the theory of cognitive dissonance. The fourth section presents a discussion on the convergence (and divergence) between decision-making according to original Institutional Economics and Behavioral Economics. Final comments, in fifth section, conclude our study.

\section{THORSTEIN VEBLEN'S INSTITUTIONAL ECONOMICS}

Original Institutional Economics is an economics approach established at the beginning of the 20th century. Historiography recognizes the great importance of this current of economic thought until the interwar period. Hodgson (2004a) states that the original institutionalism was the economics mainstream in that period. Rutherford (2011), although not agreeing with Hodgson, recognizes the extreme importance of Institutional Economics in the first half of the 20th century. The analysis of decision-making in original Institutional Economics, especially from Thorstein Veblen's perspective, relies on the role of institutions, habits, and their evolution (Hodgson, 1998). In the intellectual environment of a science dominated by a self-centered and optimizing approach to decision-making, Institutional Economics offered an alternative.

It is worth clarifying that the institutionalist perspective does not question that many human decisions are chosen from other existing alternatives based on calculations made by rational agents; in that sense, it coincides with the mainstream perspective in some circumstances. To give some examples, a surgeon who plans an operation or an investor who analyzes the composition of her/his portfolio is certainly making rational decisions, in a sense close to what the mainstream advocates, although the concept of rationality diffs between an institutional and a mainstream perspective. However, institutionalists would highlight two other aspects. The first, a more encompassing one, invites us to remember that many decisions may not go through a rational plane. Regularly, we act following other usual motivations; for example, when choosing our foods, we often follow a pattern that does not depend on the options offered to us, regardless of rational considerations we may make about our health that would suggest different choices. However,

and Behavioral Economics. Steven Pressman, one of the few authors to examine this relationship, states that K\&T's writings support Institutional Economics in several ways (see Pressman, 2006: 505). 
perhaps more important is to remember, going back to the previous example, that some decisions made by the surgeon when operating, and even by the investor when setting up her/his portfolio, reflect habits of thought that certainly do not stem from rational calculation. The surgeon wears a white coat and washes her/his hands automatically, greets her/his colleagues in the operation room following the traditions of society, the hierarchy of professions, and so on. Similarly, the investor consults the normal sources in the world of data that surrounds her/him and interprets them according to certain mental patterns she/he has developed over the years. Let us examine, then, the foundations of this school that support its analysis of decisions.

Veblenian institutionalism is based on 19th century North American pragmatic philosophy. Key concepts in Veblen's writings, such as instincts, habits, and institutions, rely on theoretical elements of North American pragmatic philosophy. The pragmatists who most influenced Veblen were Charles Peirce, William James, and John Dewey. In this regard, our goal is to highlight how the philosophy of Peirce, James, and Dewey supports the psychological aspects of Veblen's writings. Peirce's influence on Veblen's conception of scientific analysis is manifested in the latter's Darwinian approach ${ }^{5}$. For Peirce (1877), a society's culture, tradition, and prejudices can be explained by the formation of its beliefs, which affect individual behavior. Beliefs interact among themselves, giving rise to new beliefs that are fixed with certain rigidity but that can also change as new interactions occur, consequently modifying the external environment (Peirce, 1877). Veblen materialized this fixation of beliefs in his conception of institutions and habits of thought.

It is not possible to introduce the Veblenian definition of institutions without mentioning Veblen's concept of habit. For Veblen, habit and institution are associated since institutions represent the social generalization of collectively shared habits of thought (Veblen, 1898 and 1906). From Veblen's perspective, individual actions are guided by the interaction among various institutions co-existing in a society, which are transmitted by habits of thought. The interaction among institutions delimits the structure of human behavior and allows organization in thinking - expectation and action - providing shape and consistency to human activities ${ }^{6}$. For Veblen (1898 and 1906), although institutions influence human behavior at a given point in time, they are not static, and knowledge and actions arise from evolutionary processes. Griffin (1998) states that this constitutes Peirce's influence on Veblen.

Furthermore, Peirce affirms that the foundation of institutions occurs according to historical processes during which beliefs are established; Veblen affirms that

\footnotetext{
${ }^{5}$ In 1881, when Veblen was a student at John Hopkins University, he attended a course offered by Peirce, "Elementary Logic" (see Griffin, 1998; Liebhafsky, 1993; and Camic, 2012).

${ }^{6}$ In Hodgson's (2006: 2) words: Veblenian institutions would be “[...] systems of established and prevalent social rules that structure social interactions. Language, money, law, systems of weights and measures, table manners, and firms (and other organizations) are thus all institutions."
} 
habits are generated within the decision-making environment (Peirce, 1877, and Veblen, 1899c). However, the existence of evolution in institutions does not imply an improvement in them. It only shows the occurrence of a cumulative change process, in which new elements are combined with existing institutions, building new institutions or altering old ones (Veblen, 1898 and 1906). The key point of Veblen's writings is an understanding of how institutions evolve and how they influence decision-making. According to Hodgson (2004b), institutions are durable in the sense of presenting a certain stability in the expectations for specific behaviors and they create the social rules that facilitate the organization of society. Positive stimuli offer self-reinforcement to institutions. As institutions shape themselves, individual preferences change, giving rise to new perceptions and dispositions, which change individual thought and behavior (Veblen, 1899c, and Hodgson, $2002 \mathrm{~b}$ and 2003). Just as institutions shape the individual, the individual also has a degree of influence over institutions. This interaction between institutions and individuals leads to changes in some habits and, consequently, also changes institutions. Therefore, the external environment in which an individual is inserted tends to shape social behavior, although this action is not deterministic (Cordes, 2005; Latsis, 2009; and Hodgson, 2004b).

Returning to the Veblenian perspective of habits, it is possible to find issues in the writings of James and Dewey that were also central in Veblen's theory. For all these authors - Veblen (1898), Dewey (1921), and James (1890) - it is through education that habits are incorporated into social interaction groups ${ }^{7}$. According to James (1890), in many routine activities, individuals are guided by a set of habits, which are put in practice without much thinking. They are not activities that require a great deal of attention or a degree of reasoning; they simply consist of naturally following the behavior considered standard. Dewey (1921) proposed a definition close to that of James (1890), that habits imply automated actions, exercised routinely.

Veblen, James, and Dewey agree that habits are social and acquired in a group through socialization, notably through education. In addition, there are some individual peculiarities in the execution of the usual routines. All individuals within a given modern Western society, for example, are used to brushing their teeth. However, how each individual will brush her/his teeth depends on the particularity of the individual being - although this argument is present in the writings of Veblen and Dewey, it is more clearly presented in James (1890). However, according to James (1890), when analyzing any individual, it is possible to notice that there is a series of behaviors practiced daily. Some of those behaviors seem to be incorpo-

\footnotetext{
${ }^{7}$ It is important to address that William James, born in 1842, like Peirce, born in 1839, was from a generation before Veblen's, who was born in 1857. Dewey, born in 1859, was Veblen's contemporary. The age difference between Peirce and Veblen allowed the latter to be a student of the former. Indeed, Peirce only had an academic job in his life, being a professor at Johns Hopkins between 1879 and 1884 . By chance, Veblen tried to study at that university - as addressed previously, Veblen was at Johns Hopkins in 1880, before attending Yale, where he would finish his Ph.D.
} 
rated at an early age whereas others are acquired through a longer interaction of the individual with the environment that surrounds her/him during her/his life. Dewey (1921) shares the same perspective; for him, there are involuntary actions, such as breathing or digesting, and acquired actions, such as the habit of having three meals: breakfast, lunch, and dinner. Habits can be studied objectively, like physiological functions, as they are a fact, which can be determined by observing people's behavior. They can change through changes in individual or social decisions and choices. This is the main difference between a habit of conduct and a physiological process: the conduct is socially shared - it is an action, whether good or bad, that originates from living in society (Dewey, 1921). According to Veblen (1898) and James (1890), a habit is perceived when it implies a behavior. However, a habit is not like a "straitjacket" in that it does not limits an individual's actions to specific repeated behaviors; it implies only potential behavior that can be triggered by an appropriate stimulus or context. According to James (1890), Dewey (1921), and Veblen (1898), habits are influenced by past and current knowledge so that the past conditions but does not determine the present decision-making. Veblen (1898) and James (1890) argue that habits differ among individuals, as the latter aim to adapt to the demands of the external environment. Given internal pressures or external forces, the structure of habits can change. However, these shocks of change in habitual structures do not usually occur abruptly.

Part of the economics literature on Veblen, such as Almeida (2014) and Cordes (2005), recognizes that there is a fundamental element in decision-making, in addition to habits and institutions, but that it is less studied by historiography and institutionalists. This element is instinct. There is a central point for understanding Veblen's unusual approach to instinct (Almeida, 2014). Veblen's central argument about instincts is strongly linked to the rejection of the orthodox psychological theory of his time (Rutherford, 1984). Veblen (1914) diverges from the idea that instincts are purely biological impulses. Veblen (1899c and 1914) calls the impulses that are part of the unconscious, expressed in involuntary actions of biological nature, tropisms or reflexes. Veblen's instincts, on the contrary, are social processes of cumulative acquisition; therefore, they are determined by actions that are based on previous observations and/or education. To avoid conceptual confusion, we will follow Almeida's terminological distinction (2014 and 2015). We will refer to Veblen's tropism or reflex as internal impulse and we will use the term instinct in the sense it was used by Veblen ${ }^{8}$.

Veblen's (1914) unusual approach to instincts allowed him to classify intelligence, cognitive skills, and particular perceptions as part of instincts. Therefore, for Veblen, a decision-maker's environment can affect her/his instincts. Cordes (2005) reinforces this argument by stating that Veblenian instincts are cognitive mechanisms that determine particular actions and perceptions. According to Latsis (2009)

\footnotetext{
${ }^{8}$ Contemporary psychologists and philosophers often use the term instinct for what Veblen called tropism or reflex (see Almeida 2014 and 2015).
} 
and Rutherford (1984), Veblen's instincts are combined and shaped in the cultural environment. Almeida (2014 and 2015) and Rutherford (1984) consider that, for Veblen, instinct would be habits deeply rooted in the decision-making process, expressed in (individual or collective) behavior. For example, in the habit of driving, a trained driver performs numerous actions - changing gears, observing the mirrors, and others - without having to think about what she/he is doing; she/he acts instinctively because the habit of driving is already deeply rooted in her/his decisionmaking. This Veblenian perspective of the concept of instinct comes from James's writings. For James (1890), habits that have an innate tendency are called instinct. Therefore, these instincts may contain traces of education (James, 1890).

Nevertheless, Veblen classified instincts into three main types: (1) parental bent, which concerns all altruistic feelings, material care, and other people's well-being; (2) idle curiosity, which is linked to learning without a previously determined result, including scientific effort; and, (3) instinct of workmanship, which concerns the efforts to look for emulation in the social stratification that promotes socially accepted and/or desired behavior and logic (see Latsis, 2009). According to Cordes (2005), the instinct of workmanship is formed within our unconscious, which promotes work efficiency. Individuals seek emulation within the social strata to which they belong, motivated by efforts to seek a position accepted as socially superior. It is through the instinct of workmanship that the individual performs her/his activity in the best possible way. In general, historiography usually focuses on the instinct of workmanship; however, in a search for elements of pragmatic philosophy in Veblen's writings, idle curiosity plays a key role.

In this regard, Dyer (1986) and Liebhafsky (1993) address the term "musement," used by Peirce to describe an aesthetic state of mind in which a decisionmaker is confronted with an issue and seeks to solve it through a provisional solution, which is taken as a hypothesis. Veblen recognizes the peculiar state of the minds of individuals who generate hypotheses and calls these hypotheses "idle curiosity," which follows the same principle as Peirce's "musement." Investigation via "musement," in addition to making a major contribution to the development of Veblen's "idle curiosity," also provides evidence of Veblen's concern regarding the creative aspect of science, or even the interpretation of science as creative imagination. According to Dyer (1986), Veblen discusses curiosity as a characteristic of human nature, expressed by instincts, and which can vary in different environments, under different cultures. Idle curiosity is related to a propensity for disinterest, or irrelevant attention. In this sense, for both Peirce and Veblen, within the principle of adaptation, scientific investigation is an act of perception that requires an altruistic attitude from the decision-maker.

\section{DANIEL KAHNEMAN AND AMOS TVERSKY'S HEURISTICS}

This section discusses the key elements of K\&T's Behavioral Economics. They began their joint research in the 1960s; Tversky passed away in 1996, and Kahne- 
man continued their research alone (or with other co-authors) since then. In 2002, K\&T's studies received enormous recognition because, in that year, Kahneman won the Alfred Nobel Memory of Economic Sciences Award ${ }^{9}$. Kahneman said the prize should be considered as shared with Tversky ${ }^{10}$. Since the beginning of their partnership, K\&T's writings focused on the study of the elements that guide the decisionmaking of economic agents. Both psychologists by training, they sought in psychology elements for the analysis of decision-making in economic matters. For a deeper understanding of the psychological theory on which K\&T's theories are based, this study analyzes the connection of their work with the works of psychologists B. F. (Burrhus Frederic) Skinner, Albert Bandura, and Leon Festinger.

We chose to study Skinner, Bandura, and Festinger as they dealt with behavioral and cognitive issues, as K\&T did. In addition, these psychologists are of enormous importance in contemporary psychological studies. In the publication entitled "The 100 Most Eminent Psychologists of the 20th Century" (2002), Skinner occupies the first position, Bandura is fourth, and Festinger is fifth ${ }^{11}$. Skinner's studies follow the behavioral or behaviorist line whereas Bandura and Festinger present a study of social and cognitive psychology. It is important to highlight that, our references to Skinner, on one hand, and to Bandura and Festinger, on the other, are made for different reasons. K\&T's writings are characterized as being part of Behavioral Economics. It is worth emphasizing that there is a great methodological difference between Behavioral Economics and behavioral psychology, despite the common nomenclature. This study emphasizes that K\&T's writings are more closely related to social and cognitive psychology - like the writings of Bandura and Festinger - than to behavioral (behaviorist) psychology - like Skinner's studies.

K\&T's writings can be divided into two main areas: (1) criticisms of conventional economic theory and (2) a proposition of an analytical form for decisionmaking. This study focuses on the latter. Critically, according to K\&T (1983), studies based on emulating utilitarian reasoning show that individuals often fail to understand or apply logical principles as provided by orthodox economics. The latter attributes to individuals an unlimited capacity for reasoning, an approach called "substantive rationality" by Herbert Simon, one of the pioneers of Behavioral Economics (Simon, 1979). From a critical perspective, K\&T's studies were based on falsifying descriptive models of behavior present in conventional economics, especially those related to expected utility theory (K\&T, 1979). Another relevant criticism is of the basic axioms of utility theory. For K\&T, when analyzing a decision-maker, it is possible to notice that these axioms are easily violated in the case of choices under uncertainty. According to K\&T (1979), these models are un-

\footnotetext{
${ }^{9}$ The Official Web Site of the Nobel Prize, accessed on September 23, 2017; available at: https://www. nobelprize.org/search/?query=kahneman.

${ }^{10}$ The Official Web Site of the Nobel Prize, accessed on September 23, 2017; available at: https://www. nobelprize.org/search/?query=kahneman.

${ }^{11}$ Available at https://www.apa.org/monitor/julaug02/eminent.
} 
able to predict the behavior of agents; in fact, it can be said that K\&T propose a descriptive approach to the choice of agents, without, however, wholly disregarding the orthodox approach. From this perspective, the proposals of the traditional view come to be seen as normative propositions (what the agents should do in the face of choices under uncertainty) whereas K\&T's studies turn to what the agents actually do or manage to do given the limitations of their rationality (Heukelon, 2014). Judgment heuristics, according to K\&T (1974), are like thumb rules capable of offering simple and intuitive answers to complex problems. Because of heuristics, it is possible to replace a response that would be very complex with a simpler one, through a process that allows an easy prediction. To achieve such a result, decisionmakers rely on intuitive probabilities induced by the appropriate heuristics for each decision-making scenario. For K\&T (1996), heuristics act differently from a logic based on frequentist probability. If we use frequentist probability as a reference, heuristics could induce systematic statistical errors, often referred to as biases by K\&T. According to K\&T (1996), the probabilities of decision-making are related to mental models that seek an intuitive response to certain events, inferring possible decisions as appropriate, based on different heuristics. A judgment heuristic does not accurately predict the probabilities of the occurrence of the different possible alternatives. A reason that leads to "error" or bias in judgments is the different types of knowledge, beliefs, and traditions that individuals have. In this way, the results deduced, through intuition, are different for different types of individuals (K\&T, 1983). People have different perceptions of the world around them. The results of this interpretive process of reality, deduced through intuition, will be different for individuals due to the diversity of perceptions they have built about the decision-making environment in which they have been inserted (K\&T, 1983).

Concerning the idea that a decision-maker's intuition is generated from an interpretation of the world around her/him, we can relate the writings of K\&T with the studies of Skinner, Bandura, and Festinger, examining their degree of proximity. In Skinner's (1982) behaviorist analysis, human behavior can be described as a series of actions based on seeking the feeling of instant comfort that these actions can provide. This behavior is defined, according to Skinner (2002), by three principles: (1) Natural selection, which is based on Darwinian ethology, and which is found in the very nature of things: behavior is the result of the evolution process, which operates adaptively. (2) Operant conditioning, according to which an individual's behavior is reinforced if this behavior is well-accepted by the social group in which she/he is inserted. In this case, the possibility that this behavior will occur again increases; the opposite occurs when the behavior is rejected by the group and the decision-maker is punished. In this case, this conduct is inhibited and its possibility of reoccurrence is reduced. (3) The evolution of social contingencies, which are part of culture and reflect the characteristic behavior of the human species.

For Skinner (1982), the development of human behavior occurs under the influence of a selective process of social formation. During this process, the individual comes in contact with the external environment - culture, customs, and traditions - generating character traits. However, for Skinner (2002), this explanation 
presents the problems of psychologism, mentalism, or cognitivism, which imply, according to the psychologist, a neglect of important information. Once explanations of primitive cultural practices remain in the "mind of the savage," these, in turn, lead to social, cultural, and economic causes that have influenced individuals since ancient civilizations. Skinner's proposal to overcome the problem of cognitivism is to deviate from the study of mental or sentimental states and directly analyze physical or environmental causes. This analytical perspective led Skinner and behavioral psychology to a cause-effect analysis of human behavior.

Accordingly, we can affirm that both K\&T and Skinner introduce an analysis of behavior relying on instantaneous responses. Nevertheless, for Skinner, the mind is activated through stimuli from the external environment; from this perspective, the mind would be like a computer whose responses always culminate from an initial stimulus. For K\&T, on the other hand, the central aim is to understand how individuals use information previously stored in their brain in decision-making. Since the 1970s, when cognitive theory gained more attention, many authors began to question this experimentalist behaviorism studied by Skinner. For cognitivists, the physical environment is incorporated into the mind as experiences. These experiences reflect behavior stored in the mind as ideas, acts, knowledge, purpose, and so on. Many of these behavioral functions are considered to be outside external interference. We argue that K\&T's proposal is in line with the cognitive perspective. Kahneman (2011) argues that individuals' intuitive responses are related to the cognitive elements acquired by them throughout their lives. Results are achieved through the use of judgment heuristics, and, therefore, the answers may be different for different groups of individuals who have different experiences (K\&T, 1983). To understand the perspective of cognitivists, we introduce some key points from the perspective of two of their great representatives, Bandura and Festinger.

For Bandura (1969), behavior, in general, is derived from learning responses rather than learning places, resulting from an environment. According to Bandura (1969), within each social structure, decision-makers act through reinforcement contingencies. The author highlights three main types of reinforcement: (1) vicarious reinforcement, based on the observation and understanding of others' behavior; (2) cognitive reinforcement, based on the perception of the symbology of behaviors; and, (3) self-reinforcement, based on the experience accumulated by the decisionmaker. For Bandura (1969), an individual's reaction to imposed social rules and ethics is linked to the way that individual has learned to behave when faced with that environment. According to Bandura (1969), as environmental conditions are being modified, there is a need to change some patterns of conduct that were internalized by the individual during the socialization process. This occurs through an adaptive process. Therefore, old patterns are replaced by new ones, which are better adapted to the new situation, although they face some resistance, especially when they threaten widespread traditions and customs. For both Bandura and K\&T, individuals build a perception of the environment through their own experiences. People are influenced by the environment during the socialization process and these influences are stored in the mind (Bandura, 1969, and K\&T, 1974). 
In his turn, Festinger believes that the knowledge that allows a decision to be made and cognition are mixed because, for him, cognition is self-knowledge about behavior and about the environment in which the decision is made (Festinger, 1975). Accordingly, into the knowledge are incorporated feelings and desires, the understanding of the world, as well as the values and beliefs of each individual. Cognition, in general, reflects physical, social, and psychological reality. Cognitive elements that do not correspond to reality cause dissonance pressures that aim to push one to try to solve the problem. According to Festinger (1975), when analyzing two elements and verifying that one stems from the other, they will be considered consonant. If the elements are divergent, they will consequently be dissonant. However, if one element does not stem from the other and the elements do not stem from their inverse, they will be irrelevant. This approach became known as the theory of cognitive dissonance.

To show the connection between the heuristic approach in decision-making, proposed by K\&T, and the perspective of Bandura and Festinger, we need to take into account the features of what are called availability and anchoring heuristics ${ }^{12}$. An availability heuristic is based on a priori associations - those that had occurred previously - even if they are not related to the decision to be taken (K\&T, 1983). Looking for information in memory is directly associated with availability, as memory is impressed by what is most evident, that is, by the information to which memory has easier access and which, consequently, is most available (K\&T, 1974, and Kahneman, 2011). Something similar occurs with the anchoring heuristic, which is associated with the confidence that individuals have in what they are familiar with (Kahneman, 2011). The use of intuition possibly occurs due to anchoring (K\&T, 1974). According to Kahneman (2011), since individuals, via anchoring, tend to trust what seems familiar, the repetition of information can cause it to be accepted and used in decision-making, regardless of whether it is false or true ${ }^{13}$.

For K\&T (1996), availabilities are built through the interference that society exercises on the formation of the individual; this information is stored in the mind and activated in an associative way. One of our arguments in the present study is that K\&T's availability rests on Bandura's vicarious reinforcement, consequently moving away from the cause-effect relationship of Skinnerian behaviorism. For Bandura, the social learning process can occur on a vicarious basis through the observation of other people's behavior and its consequences (Bandura, 1969: 69). In this way, fast and simple responses, equivalent to those in the availability heuristic, are induced by observing the behavior of other people. This process has three effects: (1) The "modeling effect," by which the observer can incorporate new patterns of responses in her/his behavioral set by observing the behavior of others. (2) The "inhibiting effect," where what has been vicariously observed and learned

\footnotetext{
${ }^{12}$ More correctly, anchoring and adjustment heuristics.

${ }^{13}$ What is known can often be the anchor but it does not exhaust the repertoire of options. Sometimes, the anchor can be determined in a more or less random way.
} 
emphasizes to an individual how not to behave. The inhibitory effect does not always completely suppress the behavior; it can imply an availability that reduces the propensity to adopt a behavior. (3) The "response-facilitating effect," which concerns how behavior that is observed facilitates responses by the observer, who can learn something without having to live the experience. In this sense, it is vicarious learning. Although vicarious learning comprises the "modeling effect" and the "inhibiting effect," the "response-facilitating effect" concerns both vicarious learning and reinforcement, as the latter can act as availability, stimulating and facilitating already learned responses. In this case, in contrast to the first and second cases, nothing new is added to availability but a behavior is reinforced. Therefore, vicarious reinforcement, as described by Bandura, implies availability as described by K\&T. More precisely, Bandura's (1969) "response-facilitating effect” would be an availability heuristic, whereby easier questions and answers are replaced by more complex questions and answers but without incorporating new elements. In this case, events associated with previous events, whether due to repetition, frequency, or because they are fresh in the memory of individuals, tend to be chosen more frequently, inhibiting responses that are not so common.

The place of Bandura's "modeling effect" and "inhibiting effect" in the theoretical body of K\&T is more wide-ranging than the availability heuristic. According to K\&T (1983), judgment heuristics are common perceptions of a message or an event that individuals face in their daily lives. Largely, these common perceptions come from traditions and beliefs. For K\&T (1983), beliefs and traditions build informal mental models that help to define individuals' responses. Thus, individuals present different responses according to the knowledge they have acquired and according to their worldview. As in the case of Bandura's "modeling effect" (1969), individuals incorporate new patterns into their responses, according to their beliefs and traditions. According to Kahneman (2011), these beliefs and traditions can change as new elements are incorporated by the decision-maker. In K\&T's heuristics, as in Bandura's (1969) "inhibiting effect," responses may strengthen an inhibition or, on the contrary, weaken that inhibition.

Taking anchoring into account, according to Kahneman (2011), there is a phenomenon called priming effect, which concerns the associative power that a word has with another, a piece of information with another, or a behavior with another. Therefore, words, information, and repeated behavior can exercise a great deal of influence on the behavior of individuals in a society. For both Kahneman (2011) and Bandura (1969), learning can occur without the agent being aware of it, which is especially important in the case of decision-makers. Kahneman explains automatic decisions via the priming effect, and Bandura does the same via reinforcement. Automatic decision-making occurs through repetition and reinforcement of information. In situations where it is crucial for decision-makers to be aware that they are learning, K\&T (1996) argues that cognitive comfort needs to be generated. It is not enough to transmit a message; it should generate cognitive comfort in the recipient. We argue that this cognitive comfort is similar to Festinger's (1975) cog- 
nitive consonance. For Festinger (1975), when an individual needs to make a decision, some consonance will usually be created.

We can affirm that there is a classic example of cognitive consonance. Festinger (1975) cites the example of a smoker who has no negative information about cigarettes. From the moment that this individual has access to information about the harmful effects of cigarettes, the decision to continue smoking presents a dissonance because the new information generates an incompatibility with the behavior: due to the new information, the decision-maker does not want to behave in a way that is harmful to herself/himself. The individual tries to reduce or end the dissonance in two ways: (1) she/he can continue to smoke, emphasizing the benefits of smoking, for example, decreased anxiety, which would decrease the dissonance or (2) she/he can quit smoking, which would make the dissonance disappear. Festinger (1975) recognizes the simplicity of the example: since the information that smoking harms health is socially disseminated, smokers generate cognitive consonance as described in (1). In Festinger's approach, cognition is a set of ideas, beliefs, and opinions that influence an individual's behavior, and dissonance occurs when there is a conflicting relationship among cognitions.

Festinger's cognitive consonance is similar to the anchoring heuristic, as the decision-maker deals with information as something that should be accepted when she/he considers that a relationship among her/his cognitions is consonant. Consequently, cognitive consonance does not depend on whether the information is negative or positive but the relationship that the decision-maker has with the information. Later, Kahneman (2011) associates anchoring with cognitive comfort. According to Kahneman (2011), when individuals' opinions are convergent, they generate cognitive comfort; if they are divergent, they create cognitive discomfort. Cognitive comfort, for Kahneman (2011), occurs when the individual has a feeling of familiarity with the information. When the individual makes a choice that seems right, she/he reduces the dissonance, thus generating a feeling that she/he has made the right choice.

According to Festinger (1975), the more social factors are related to an individual's set of cognitive elements, the greater the magnitude of consonance or dissonance. When the elements involve beliefs, values, and traditions, the consonance or dissonance tends to be greater. Another factor that reduces the magnitude of the dissonance, according to Festinger (1975), is the number of people who hold the same opinion. If more people agree, the smaller is the magnitude of the dissonance produced by the disagreement, increasing the degree of consonance. The support of a social group has great potential for reducing dissonance; this is because the individual is influenced by this group. Once again, Festinger's theory about individuals' reinforced confidence in what seems familiar can be considered compatible with the core of the anchoring heuristic. Both Festinger (1975) and Kahneman (2011) affirm that when news spreads through the media and people start to reproduce it, individuals experience a cognitive consonance supported by the social group. For Kahneman (2011), the availability of interpretation and beliefs present biases that are activated by associative memory. Therefore, the reproduction of 
"mass phenomena" represents a pursuit for the reduction of dissonances. It can occur on a large scale or in an isolated group of people. Social learning is a process in which the views of K\&T, Bandura, and Festinger converge. Individuals perceive reality based on social learning but when they are conditioned or restricted, they tend to respond quickly.

\section{CONVERGENCE OF VEBLEN'S INSTITUTIONALISM AND K\&T'S BEHAVIORAL APPROACH}

After introducing the psychological basis of Veblen's institutionalism and K\&T's behavioral approach - focusing on the role of heuristics in decision-making - in the second and third sections, respectively, in this section we introduce the elements that support the existence of a significant convergence of these approaches. Clearly, in general terms, we can say that, for Veblen, the central element of decision-making is institutions, habits, and instincts whereas, for K\&T, the key element is judgment heuristics. In this section, we explore synergistic elements between Veblen's institutions, habits, and instincts and K\&T's heuristics. However, we first make some brief methodological observations.

Veblen (1899c) analyzes the evolutionary process from barbaric societies to the establishment of the capitalist system. He expresses a strong concern for understanding how habits and institutions change, which not only generated industrial activities but also, at the same time, preserved some interests rooted in society, which were developed in other stages in human history. Habits and institutions are transmitted to other generations through psychological factors that are influenced by individuals, as highlighted in the second section. The result is pre-selected patterns becoming institutionalized. Abandoning habits is something that can cause an institutional change, but it can be a difficult task as habits are not only elements of an institutional structure but also part of the psyche of decision-makers (Veblen, 1899c). The method of analysis of the evolutionary process used by Veblen to explain social evolution relies on the Darwinian rejection of teleology. For Veblen, this became an essential element for post-Darwinian scientific study within economics and the social sciences. From evolutionary theory, Veblen incorporated the concept of cumulative causality (Hodgson, 2004a).

On their part, K\&T (1979) and Kahneman (2011) question the utilitarian rationality of agents through experiments on the behavior of the decision-maker. For K\&T, when faced with a situation in which they need to make decisions under uncertainty, people entrust their responses to heuristic shortcuts. Many decisions are based on beliefs built about facts and/or processes that are not known for certain. During this process, people search their mental system for situations they have experienced, or stored memories, which may generate biases. The latter represent anomalies from the perspective of traditional economics theory. When analyzing the decision-making of an economic agent, behaviorists associate individuals' decisions with social factors such as beliefs, traditions, and culture. The method used 
by $K \& \mathrm{~T}$, which led to the questioning of the rationality of economic agents, is inductive experimentalism. The authors worked with experiments as a source of empirical hypotheses, proving the limitation of utilitarian theory with regard to the substantive rationality of economic subjects. This was shown by a series of tests that support the heuristics theory and perspective biases.

Hence, it is possible to understand that there is a great difference in the purpose of the two perspectives. Veblen is concerned with explaining the process of social evolution to understand the formation of institutions in modern societies. K\&T's central concern is experiments and tests that question the conclusions of utilitarian economics. In this section, we argue that, despite this difference, the understanding of Bandura's and Festinger's writings as sources of K\&T's psychological conception makes it possible to suggest that Veblen's and K\&T's approaches have converging elements with regard to the analysis of economic decision-making.

A key point for the convergence of the two approaches, explicit in K\&T's and implicit in Veblen's work, is what the former called ease of decision-making. In K\&T's view, availability occupies a central place in a decision-maker's analytical perspective since memory creates easy access to certain kinds of information (K\&T, 1974). Consequently, heuristics correspond to fast responses that do not require much effort, when individuals make less complex decisions. In turn, a habit, according to Veblen, can be understood as a way for the decision-maker to behave without investing much effort, because habits are automated (Hodgson, 2004b). In addition, in Veblen's approach, there are habits deeply rooted in individuals' decision-making. Veblen understood that those habits are similar to biological instincts (internal impulses).

An illustrative example is as follows: imagine a consumer in a supermarket in front of the cookie shelf. In general, the shelf presents a great diversity of goods with great similarity. An encompassing and completely rational understanding of all types of cookie would result in overly complex decision-making. First, a criterion should be established, followed by an application of this criterion over the set of possibilities. For K\&T, the decision-maker's memory would introduce an easy form of choice, and this facilitating element could be the information that is most relevant for the consumer. It could be an advertisement she/he recently watched on television, information from an informal conversation with friends, or the recognition of a usual packaging. For Veblen, the consumer would choose according to her/his consumption habit, and this habit would simplify her/his decision-making. That habit would have individual aspects, but at the same time, it would be a consequence of the evolution of the institutions of society - for example, the established advertising channels or mechanisms of food distribution. In this way, we can identify an approximation between K\&T's availability heuristic and Veblenian habits when we address how decision-making is facilitated. Availability and habits facilitate decision-making in a similar way. However, it is worth noting that Veblen is much more emphatic about the importance of historicity in establishing a habit than $K \& T$ are regarding the availability heuristic. It is not to say that K\&T was silent on the importance of past events. Nevertheless, the investigation of social and 
cultural origins and their changes over time until the system that currently allows decisions to be made was reached is not the analytical goal of Behavioral Economics but rather Institutional Economics.

Still, understanding Bandura's and Festinger's writings as elements that underlie the psychological precepts of K\&T allows us to better explore the role of historicity in the behavioristic approach. For Veblen, the importance of history in decision-making is central because the habits of thought carry what has been learned and institutionalized in society (Veblen, 1898 and 1899c). The use of habits of thought in decision-making represents an educational process occurring during the interaction of individuals in society (Veblen, 1898; Dewey, 1921; and James, 1890). K\&T recognized the role of history by highlighting the importance of availability. Some heuristics are present in decision-making due to the memory that decisionmakers have of previous events (K\&T, 1874 and 1983). One of our arguments is that the role of memory stems from what has been vicariously learned through the "modeling effect," the "inhibiting effect," and the "response-facilitating effect" (Bandura, 1969).

The similarity of K\&T's approach of availability to the concept of Veblenian habit also reverberates in the socialization process. If something is vicariously learned, then there exists a model of behavior; if we are dealing with a socialized individual, the model of behavior does not play this role only in the decisionmaking of a single individual. As a result, the modeling, inhibiting, and responsefacilitating effects are the result of social interaction. Therefore, if we accept that Bandura's writings create the psychological basis of K\&T's work, elements of the socialization process exist in availability. Learning does not mean that events must be experienced by the individual herself/himself, as learning also occurs by observing the behavior of others. As Bandura (1969) explains, the individual incorporates the others' behaviors and starts to reproduce them through a vicarious, cognitive, or self-reinforcement process. The knowledge one acquires is modified as new learning processes are incorporated into existing ones. Social learning comprises the beliefs, traditions, and culture of a given country and/or region, influencing the cognitive formation of the individual who is part of that society. For Veblen, it is through these social characteristics that habits are socially formed and shared by the interaction among institutions.

Based on this interpretation, we can say that both the availability heuristic and Veblenian habits are linked to the situations previously experienced, to the behaviors learned throughout life, and to the socialization process. The same logic can be extended to the anchoring heuristic because what is learned is stored in the cognitive system of decision-makers and implies a series of cognitive consonances (Festinger, 1975). Cognitive consonances are those that generate the familiarity present in the anchoring, that is, they are the "soul" of intuition. Here, we suggest an approach to instinct as the one stated by Veblen. When a habit is so internalized as to be able to function as an instinct, it is understood as a behavior as natural as an internal impulse (instinct in the biological sense). What a decision-maker considers natural can suggest familiarity with a particular way of making a decision. In 
the second section, we highlighted that one of the instincts that Veblen deeply analyzed was the instinct of workmanship. According to that instinct, the emulation of the upper social strata can be seen as a common behavior so the instinct of workmanship could be seen as an expression of anchoring.

The cognitive consonances of the anchoring heuristic are also associated with the socialization process and the culture in which the decision-maker was raised, since decisions follow a socially accepted pattern. For Festinger (1957), several times, when an individual faces a situation where she/he needs to express a public opinion, she/he will choose an answer that she/he believes can be accepted, even though her/his intimate opinion is different from the social opinion. Veblen highlights a similar point in his analysis of the conspicuous consumer (Veblen, 1899c). For Veblen, societies developed to a level where there is a well-defined social stratification and the classes considered socioeconomically inferior emulate the superior ones. This emulation is more explicit in goods that are consumed publicly (Veblen, 1899c). Once again, the large difference we see between Veblen's and K\&T's approaches is the emphasis on historicity. Although, for K\&T, cognitive dissonance implies the absence of anchoring, for Veblen, cognitive dissonance occurs due to an individual's lack of ability to understand the relationship between institutionalized procedures and their expected results, as institutions evolve, and mental models need to be revised.

\section{FINAL COMMENTS}

In this paper, we present two non-traditional economic approaches and examine the possibility of their convergence. These approaches are original institutionalism, from its Veblenian aspect, and K\&T's Behavioral Economics, focusing primarily on the importance of heuristics for decision-making. We took into account possible psychological bases for these approaches. In the case of Veblenian institutionalism, this psychological basis was North American pragmatic philosophy. In the case of K\&T's approach, it was the writings of psychologists Albert Bandura and Leon Festinger. The approach of linking Veblen with pragmatists is not uncommon in historiography but the search for psychological bases in the writings of $K \& T$ is an element of this study's originality. Concerning Veblenian institutionalism, the contributions of William James, John Dewey, and Charles Peirce are associated with Veblen's concepts of institutions, habits, and instincts. A reading of K\&T's writings according to Bandura and Festinger offers a psychological framework for Behavioral Economics that is distinct from behavioral psychology and that is closer to social learning processes. In terms of the convergence of the two approaches, we offer the finding that the availability heuristic is similar to the concept of habit as proposed by Veblen whereas the anchoring heuristic is similar to the Veblenian concept of instincts. However, it is worth noting that although both approaches deal with socialization processes, the role of history and its importance is much more important in institutionalism. Finally, it should be noted that this study does 
not intend to exhaust, in any way, the possibilities of analyses that contemplate the relations between Veblenian institutionalism and K\&T's Behavioral Economics.

\section{REFERENCES}

Almeida, F. (2014) “Thorstein Veblen and Albert Bandura: A Modern Psychological Reading of the Conspicuous Consumer" Journal of Economic Issues, 48(1): 109-122

Almeida, F. (2015) "The psychology of early Institutional Economics: the instinctive approach of Thorstein Veblen's conspicuous consumer theory”. EconomiA, 16(2): 226-234

Bandura, A. (1969) Modificação do Comportamento. Rio de Janeiro: Interamericana

Camic, C. (2012) "Schooling for Heterodoxy: On the Foundations of Thorstein Veblen's Institutional Economics" In: Reinert, E and Viano, F. Thorstein Veblen: Economics for an Age of Crisis. Londres: Anthem Press

Colander, D. (2000) “The Death of Neoclassical Economics" Journal of the History of Economic Thought, $22(2): 127-143$

Cordes, C. (2005) “Veblen's 'Instinct of Workmanship,' Its Cognitive Foundations, and Some Implications for Economic Theory" Journal of Economic Issues, 39(1): 1-20

Dequech, D. (2007) “Neoclassical, mainstream, orthodox, and heterodox economics" Journal of Post Keynesian Economics, 30(2): 279-302

Dewey, J. (1921). Human nature and conduct: an introduction to social psychology. Nova York: DC Heath \& Co Publishers

Dyer, A. (1986) "Veblen on scientific creativity the influence of Charles S. Peirce" Journal of Economic Issues, 20(1): 21-41

Festinger, L. (1975) Teoria da Dissonância Cognitiva. Rio de Janeiro: Zahar

Griffin, R. (1998) "What Veblen owed to Pierce - the social theory of logic" Journal of Economic Issues, 32 (3): 733-757

Haggbloom, S., Warnick, R., Warnick, J., Jones, V., Yarbrough, G., Russell, T., Borecky, C., McGahhey, R., Powell III, J., Beavers, J., Monte, E. (2002) “The 100 Most Eminent Psychologists of the 20th Century." Review of General Psychology, 6(2): 139-152.

Heukelon, F. (2014). Behavioral Economics: a History. Cambridge: Cambridge University Press.

Hodgson, G. (1998) "The Approach of Institutional Economics" Journal of Economic Literature, 36(1): $166-192$

Hodgson, G. (2003) "The hidden persuaders: institutions and individuals in economic theory" Cambridge Journal of Economics, 27(2): 159-175

Hodgson, G. (2004a) The Evolution of Institutional Economics: Agency, Structure and Darwinism in American Institutionalism. Londres: Routledge

Hodgson, G. (2004b) “Reclaiming habit for Institutional Economics” Journal of Economic Psychology, 25(5): 651-660

James, W. (1890) The principles of psychology: Volume 1. Nova York: Cosimo

Kahneman, D. (2011) Thinking, Fast and Slow. Nova York: Macmillan

Kahneman, D.; Tversky, A (1974) “Judgment under Uncertainty: Heuristics and Biases” Science - New Series, 185(4157): 1124-1131

Kahneman, D.; Tversky, A. (1979) "Prospect Theory: an analysis of decision under risk" Econometrica, 47(2): 263-291

Kahneman, D.; Tversky, A. (1983) "Extensional Versus Intuitive Reasoning: The Conjunction Fallacy in Probability Judgment” Psychological Review, 90(4): 293-315

Kahneman, D.; Tversky, A. (1996) “On the Reality of Cognitive Illusion” Psychological Review, 103(3): $582-591$

Latsis, J. (2009) "Veblen on the machine process and technological change" Cambridge Journal of Economics, 34(4): 601-615 
Liebhafsky, E. (1993) “The influence of Charles Sanders Pierce on Institutional Economics” Journal of Economic Issues, 27(3), 741-754.

Peirce, C. (1877) “The fixation of belief” In S. Haack, Lane, R. (2006). Pragmatism, old \& new. Nova York: Prometheus Books.

Pressman, S. (2006). "Kahneman, Tversky and Institutional Economics". Journal of Economic Issues, 40 (2): 501-506.

Rutherford, M. (1984) "Thorstein Veblen and the processes of institutional Change" History of Political Economy 16(3): 331-348

Rutherford, M. (2011) The institutionalist movement in American economics, 1918-1947: science and social control. Cambridge: Cambridge University Press

Sent, E.M. (2004) "Behavioral Economics: how Psychology made its (limited) way back into Economics" History of Political Economy, 36 (4): 735-760.

Simon, H. A. (1979) "Rational decision making in business organizations" American Economic Review, 69 (4): 493-513.

Skinner, B. F. (2002) Questões Recentes na Análise Comportamental. São Paulo: Papirus

Skinner, B. F. (1982) Sobre o Behaviorismo. São Paulo: Cultrix

Veblen, T. (1998) "Why is economics not an evolutionary science?" Cambridge Journal of Economics, 22(4): 403-414. [Originalmente publicado em 1898 no The Quarterly of Economics, July: 373 397].

Veblen, T. (1899a) “The Preconceptions of Economic Science I” The Quarterly Journal of Economics, 13(2): 121-150

Veblen, T. (1899b) “The Preconceptions of Economic Science II" The Quarterly Journal of Economics, 13(4): 396-426

Veblen, T. (1899c) [2007] The Theory of the Leisure Class. Nova York: Penguin Books

Veblen, T. (1900) “The Preconceptions of Economic Science III” The Quarterly Journal of Economics, 14(2): 240-269

Veblen, T. (1906). "The place of science in the modern civilization” The American Journal of Sociology, 11(5): 585-609

Veblen, T. (1914) The instinct of workmanship and the state of the industrial arts. Nova York: Cosimo Books 